\title{
Total Hip Replacement After Childhood Osteotomy: A Cohort Study
}

\section{Meilyn Muskus ${ }^{1 *}$, Camilo Cabezas ${ }^{2}$, Omar Herrera ${ }^{2}$ and Hugo Rodriguez $^{1}$}

${ }^{1}$ Department of Orthopedics and Traumatology, Hospital Infantil Universitario de San José, Faculty of Medicine, Fundación Universitaria de Ciencias de la Salud, Bogotá, Colombia

${ }^{2}$ Orthopedic Surgeon of the Fundación Universitaria de Ciencias de la Salud, Bogotá, Colombia

*Corresponding Author: Meilyn Muskus, Department of Orthopedics and

Traumatology, Hospital Infantil Universitario de San José, Faculty of Medicine,

Fundación Universitaria de Ciencias de la Salud, Bogotá, Colombia.
Received: November 12, 2020

Published: April 05, 2021

(C) All rights are reserved by Meilyn

Muskus., et al.

\section{Abstract}

Aim: Developmental hip dysplasia is a common disease and if not treated, it may cause secondary hip osteoarthrosis, and this may ultimately lead to total hip replacement in adulthood. Hence, multiple childhood osteotomies have been developed over time to prevent such incidence. The purpose of this study is to determine whether an osteotomy around the hip can delay the total hip replacement surgery and as a second objective evaluate the degree of technical difficulty involved in an arthroplasty, with and without previous osteotomy, in patients with developmental hip dysplasia.

Materials and Methods: This retrospective cohort study involved patients with a history of dysplasia and total hip replacement done between February 2007 and January 2017, comparing patients who underwent osteotomies around the hip (n = 54) and those who did not $(\mathrm{n}=135)$. However, patients diagnosed with Crowe III/IV requiring subtrochanteric ostectomy at the time of the replacement were excluded. The technical difficulty of the procedure was evaluated considering the surgical time and intraoperative bleeding as outcomes.

Results: Overall, 189 hip arthroplasties were analyzed in 173 patients with a history of developmental hip dysplasia, of which 54 had osteotomy around the hip. The average age at which the arthroplasty was performed in patients without previous osteotomy was 55.1 years $(\mathrm{p}<0.001)$ compared to patients with previous osteotomy that was 42.2 years $(\mathrm{p}<0.001)$. The surgical time and intraoperative bleeding were higher in the group of patients with previous osteotomy and it was possible to demonstrate that this medical history increased the risk of having a prolonged surgical time (5.46 times; $p<0.001)$ and an increased risk of higher intraoperative bleeding (6.08 times; $\mathrm{p}<0.001)$.

Conclusion: Patients with osteotomies around the hip required hip arthroplasty surgery earlier and having a previous osteotomy made the overall procedure longer in surgical time and increased intraoperative bleeding.

Keywords: Total Hip Replacement; Developmental Hip Dysplasia; Pelvic Osteotomies; Surgical Time; Intra-Operative Bleeding

\section{Introduction}

Developmental hip dysplasia is a disease with a wide spectrum pathology due to its multifactorial characteristic and its relation- ship with different populations. The condition may cause multiple or single deformities such as subluxation, instability, dislocation, and dysplasia of the femoral head or/and acetabulum. The persis- 
tence of this condition may eventually cause degenerative hip joint disease, limb-length discrepancy with a flexion/adduction deformity, abnormal gait, back pain, postural scoliosis, and ipsilateral genu valgus followed by arthritis of the knee in both childhood and adulthood. In Africa, the incidence in newborn babies with this pathology is 0.06 per 1000, among Native Americans around 76.1 per 1000 are affected [1]. In 1996, 7\% of the total population in Colombia were affected by this condition [2].

In the past, multiple researchers including Tonnis [3], Severin [4], Crowe [5], Hartofilakidis [6] and others, have been trying to classify and develop a treatment methods for this disease. At the end, despite some differences, all agreed in dividing the patients according to the femoral head position. This means, if it is inside the acetabulum (reduced) or if it is dislocated, with or without neo-acetabulum formation.

Some authors have found a direct relationship of osteoarthrosis with dysplasia and the normal course of the disease [7-9] this trying to determine what leads to joint degeneration and its prevention. Osteoarthrosis could be explained as hip dysplasia compromises the normal development of the acetabulum, femur or both by producing changes in the normal anatomy. The absence of normal forces that form the acetabulum causes a smaller native acetabulum with absence of anterior wall, coxa valga and increased femoral anteversion among other anatomical changes [10]. In the attempt to correct these changes on the normal anatomy by trying to improve the biomechanics of the hip and acetabular - femoral head relation, multiple childhood and adolescent osteotomies have been developed for example: The single innominate, double innominate, triple innominate, spherical periacetabular, Bernese (Ganz), Chiari for salvage and intertrochanteric osteotomies [11]. All these have been established over time to prevent the progression of the dysplasia and changing the natural history of the disease [12].

However, dysplasic hips without any treatment can remain free of radiological osteoarthrosis for around 27 to 57 years [13]. For both groups of patients (with and without treatment) the outcome remains the same, the need for total hip replacement, what could vary are the conditions under which the procedure is performed. In previous studies, the results of total hip replacement with a history of previous osteotomy have shown a survival rate of $71.2 \%$ [14] and a complication rate of $13 \%$ [15] with reports indicating increased bleeding and longer surgical times compared to the control group [16-18].
To our knowledge, no article has evaluated the outcome in terms of age at which the total hip replacement was done in patients diagnosed with developmental hip dysplasia, with and without previous osteotomy. In past studies, osteotomy and no osteotomy groups are compared to determine whether it modifies the survivorship of hip replacements, functional scores and complications [19-21], which are beyond the scope of this article. This paper is attempting to evaluate whether osteotomy can postpone the natural history of the disease. This will enable surgeons/clinicians to identify the risks regarding the risk of needing transfusion, and in young patients with diagnosis of osteoarthritis give a prognosis of time in which a replacement may be required. Therefore, the objective of the present study is to determine whether the osteotomy delayed the age of total hip replacement and, as a secondary objective, to evaluate the degree of technical difficulty during the arthroplasty procedure, in patients with and without previous osteotomy, taking bleeding and surgical time as the associated factors.

\section{Materials and Methods}

Institutional review board approval from the participating center was obtained before initiation of this study. A retrospective cohort study was designed and conducted among patients operated with total hip replacement between February 2007 and January 2017, with a history of developmental hip dysplasia with osteotomies around the hip and a control group who did not. Prior to the study, approval from the research and ethics committee was obtained.

The inclusion criteria were: 1 . Patient with developmental hip dysplasia with or without previous osteotomy, 2. Age limit: above 18 years, 3. Minimum follow-up of 1 year, 4. Patients classified Tonnis II/III arthritis, 5. Patients with complete medical records including preoperative hemoglobin levels. Patients 1 . Who were diagnosed with Crowe III/IV and required subtrochanteric ostectomy during the arthroplasty, 2. Patients lost during follow-up, 3. Patients who received hip arthroplasty at other institutions were excluded. Crowe III/IV patients with ostectomy were excluded from this study as it was considered to be a more complex procedure that cannot be compared with a conventional primary replacement with longer surgical times [18].

The technical difficulty of the procedure was evaluated by considering the surgical time in minutes and the intraoperative bleeding in milliliters. Intraoperative bleeding was quantified as the total 
blood loss collected in the cannister and only the fully saturated surgical sponge was accountable for $100 \mathrm{ml}$.

The study population was obtained from the hospital records, the first selection was done using the code of the procedure and the diagnosis of dysplasia. Afterwards, the medical records were reviewed one by one to assess if they have met the requirements, 2 researchers worked on the files and the other two in the analysis. This was confirmed using the preoperative AP pelvis radiographs and measurements described in previous reports (lateral center edge angle, Tonnis angle, acetabular version, femoral head extrusion) were used as reference to confirm the hip dysplasia diagnosis [22] at this point the patients were involved in the trial. All patients from both the groups were classified as Tonnis III at the time of surgery to make them comparable in terms of hip arthrosis. The patients without osteotomy (from now on the control group) was matched with the osteotomy group by gender, body mass index and time of surgery ( \pm 1 year) with a proportion of one osteotomy patients match with 2.5 control patients (1:2.5) per case. Demographic data, dates of procedure, type of procedure and contact information were obtained from the medical records. A minimum follow-up of 1 year was carried out, that made possible to expand the cohort and monitor any early complications (range 3 year to 10 years).

\section{Surgical technique}

All hip arthroplasties were performed in lateral decubitus position through a posterior approach with cementless acetabular component and an additional screw fixation if required. When insufficient coverage was observed during the cup trial autograft was used to augment and secure the cup. All femoral components used were also cementless devices.

\section{Statistical analysis}

Measures of central tendency and dispersion were obtained for the variables of quantitative nature. The comparisons were made using parametric t-student test or Mann Whitney nonparametric $\mathrm{U}$ test based on whether the variable meets normal criteria or not. For the qualitative variables, the frequencies and proportions were obtained, and the comparisons were made using Pearson chi-square test $\left(\mathrm{X}^{2}\right)$ when the expected values were greater than 5 , otherwise the Fisher's exact test was used.

To evaluate the technical difficulty of the hip arthroplasty procedure, surgical time and intraoperative bleeding were considered. In a review study by Duncan., et al. they reported values of 97 minutes of surgical time and $448 \mathrm{ml}$ of the intraoperative bleeding $[14,16,23,24]$, these were taken as the cut-off points in our study as the best results reported in the literature. The patients were categorized based on the cut-off point and a univariate analysis was carried out to determine which variables could be potential independent predictors for the patient to have prolonged surgical time and greater intra-operative bleeding. Hence, to determine the variables that were independently associated with the proposed outcomes, a logistic regression analysis was performed including those variables with minimally correlated and significant in the univariate analysis $(\mathrm{p}<0.250)$. Odd Ratios and 95\% CI are reported, and predictions of success.

The analyses were performed using IBM SPSS Statistics $®$ (version 21).

\section{Results}

A total of 189 hip arthroplasties were analyzed, some had bilateral hip arthroplasty two stage according to the symptoms. At the end 173 patients, who met the inclusion criteria were identified and further classified into two groups. Table 1 shows the characteristics of the total patient sample. The control group was formed with 135 patients (71\%) without osteotomies around the hip, with a proportion of $79 \%$ (107 cases) women and an average age of 59 \pm 12.1 years old at the time of joint replacement. The right hip was operated in $60 \%$ of the patients (81 cases) and $30 \%$ had bilateral hip dysplasia (41 cases). The average follow-up of the patients since the joint replacement was $5.9 \pm 2.5$ years.

\begin{tabular}{|l|c|c|}
\hline Gender & & \\
\hline Female & 152 & $(80.4 \%)$ \\
\hline Male & 37 & $(19.6 \%)$ \\
\hline Bilateral dysplasia & 127 & $(67.2 \%)$ \\
\hline Age at the time of arthroplasty (years) & 51.4 & \pm 12.9 \\
\hline Follow-up within the study (years) & 4.3 & \pm 2.7 \\
\hline Laterality & & \\
\hline Left & 85 & $(45.0 \%)$ \\
\hline Right & 104 & $(55.0 \%)$ \\
\hline Surgical Time (minutes) & 112.4 & \pm 39.6 \\
\hline Intraoperative bleeding (milliliters) & 540.47 & \pm 261.5 \\
\hline Preoperative hemoglobin & 14.0 & \pm 1.5 \\
\hline Postoperative hemoglobin & 10.7 & \pm 1.8 \\
\hline Need for transfusion & 53 & $(28.0 \%)$ \\
\hline Bone Graft Application & 17 & $(9.0 \%)$ \\
\hline Nerve injury & 2 & $(1.1 \%)$ \\
\hline $\begin{array}{l}\text { Results of the group are presented in absolute frequencies and } \\
\text { proportions in parentheses, Averages } \pm \text { standard deviation }\end{array}$ \\
\hline
\end{tabular}

Table 1: Demographic characteristics of the study population

$$
\text { ( } \mathrm{n}=189 \text { ). }
$$


The second group, 29\% of the patients (54 cases) undergone previous osteotomies around the hip. In this group, 83\% were female ( 45 cases) with an average age at the time of joint replacement of $42.2 \pm 9.4$ years. The most frequently operated hip was the left one in $57 \%$ of patients ( 31 cases) and $38.9 \%$ had a history of bilateral hip dysplasia (21 cases). The average follow-up of patients since joint replacement was $7.4 \pm 3$ years. Table 2 represents the characteristics of the patients with osteotomies around the hip who underwent joint replacement.

\begin{tabular}{|l|c|c|}
\hline Gender & & \\
\hline Female & 45 & $(83.3 \%)$ \\
\hline Male & 9 & $(16.7 \%)$ \\
\hline Bilateral dysplasia & 21 & $(38.9 \%)$ \\
\hline Age of realization of osteotomy (years) $*$ & 10.1 & {$[1-47]$} \\
\hline Follow-up within the study (years) $\dagger$ & 7.4 & \pm 31.6 \\
\hline Laterality & & \\
\hline Left & 23 & $(42.6 \%)$ \\
\hline Right & 31 & $(57.4 \%)$ \\
\hline Procedure performed & & \\
\hline Pelvic osteotomy & 44 & $(81.5 \%)$ \\
\hline Femoral osteotomy & 4 & $(7.4 \%)$ \\
\hline Pelvic and femoral osteotomy & 6 & $(11.1 \%)$ \\
\hline Number of surgeries performed before THR & & \\
\hline One & 32 & $(59.3 \%)$ \\
\hline Two & 12 & $(22.2 \%)$ \\
\hline Three or more & 10 & $(18.5 \%)$ \\
\hline Resuls of the group are presented in 6 (1) & \\
\hline
\end{tabular}

Results of the group are presented in absolute frequencies and proportions in parentheses; * Age at the time of the first surgery is presented average and range; $†$ Average \pm standard deviation; THR: Total Hip replacement

Table 2: Characteristics of patients with previous osteotomy

$$
(n=54) \text {. }
$$

The analysis of the joint replacements for each group was performed (Table 3). There was a significant difference in age of the patients with previous osteotomy (42.2 \pm 9.4 years) and the control group ( $55.1 \pm 12.3$ years; $\mathrm{p}<0.001$ ). Additionally, there was also a significant increase in the surgical time of patients with osteotomy (136.2 \pm 46.7 minutes) versus the control group (102.9 $\pm 31.9 ; \mathrm{p}<0.001$ ). A statistically significant difference was found between the two groups in terms of intraoperative bleeding, the control group had $489.3 \pm 200.1 \mathrm{ml}$ versus $668.5 \pm 343.6 \mathrm{ml}$ in pa- tients with osteotomy $(\mathrm{p}<0.001)$. Of the 54 cases who underwent joint replacement with a history of osteotomy, 5 patients required removal of some osteosynthesis material. Though patients with previous osteotomy had higher intraoperative bleeding, no differences were found in the pre- and post-operative hemoglobin level or in the requirements of an eventual transfusion.

\begin{tabular}{|c|c|c|c|c|c|}
\hline \multirow[b]{2}{*}{ Female gender } & \multicolumn{2}{|c|}{$\begin{array}{c}\text { Without prior } \\
\text { osteotomy } \\
\text { (n=135) }\end{array}$} & \multicolumn{2}{|c|}{$\begin{array}{l}\text { With previous } \\
\text { osteotomy } \\
(n=54)\end{array}$} & \multirow{2}{*}{$\begin{array}{c}\mathbf{p} \\
0.524 \dagger\end{array}$} \\
\hline & 107 & $(70.4 \%)$ & 45 & $(83.3 \%)$ & \\
\hline Right laterality & 81 & $(60.0 \%)$ & 23 & $(42.6 \%)$ & $0.030 \dagger$ \\
\hline $\begin{array}{l}\text { Bilateral dys- } \\
\text { plasia }\end{array}$ & 41 & $(30.4 \%)$ & 21 & $(38.9 \%)$ & $0.260 \dagger$ \\
\hline Age (years) & 55.1 & \pm 12.3 & 42.2 & \pm 9.4 & $<0.001 *$ \\
\hline $\begin{array}{l}\text { Surgical time } \\
\text { (Minutes) }\end{array}$ & 102.9 & \pm 31.9 & 136.2 & \pm 46.7 & $<0.001 *$ \\
\hline $\begin{array}{l}\text { Intraoperative } \\
\text { bleeding (mil- } \\
\text { liliters) }\end{array}$ & 489.3 & \pm 200.1 & 668.5 & \pm 343.6 & $<0.001 *$ \\
\hline $\begin{array}{l}\text { Preoperative } \\
\text { hemoglobin }\end{array}$ & 13.9 & \pm 1.5 & 14.1 & \pm 1.6 & $0.745^{*}$ \\
\hline $\begin{array}{l}\text { Postoperative } \\
\text { hemoglobin }\end{array}$ & 10.8 & \pm 1.8 & 10.6 & \pm 1.7 & $0.561 *$ \\
\hline $\begin{array}{l}\text { Need of trans- } \\
\text { fusion }\end{array}$ & 34 & $(25.2 \%)$ & 19 & $(35.2 \%)$ & $0.167 \dagger$ \\
\hline $\begin{array}{l}\text { Bone Graft Ap- } \\
\text { plication }\end{array}$ & 10 & $(7.4 \%)$ & 7 & $(13.0 \%)$ & $0.228 \dagger$ \\
\hline Nerve injury & 1 & $(0.7 \%)$ & 1 & $(1.9 \%)$ & $0.491 \neq$ \\
\hline \multicolumn{6}{|c|}{$\begin{array}{l}\text { Results of the group are presented in absolute frequencies and } \\
\text { proportions parentheses, and average } \pm \text { deviation standard; * } \\
\text { T-student for independent samples; } \uparrow X^{2} \text { of Pearson; } ¥ \text { Fisher's } \\
\text { exact test }\end{array}$} \\
\hline
\end{tabular}

Table 3: Analysis of joint replacements made in each group.

Technical difficulty of hip arthroplasty with and without prior osteotomy

The univariate analysis (Tables 4 and 5) determined that factors such as previous osteotomies performed in the hip, the age in which the joint replacement was performed, medical history of bilateral dysplasia and the application of bone graft in the acetabulum to treat bone defects were the potential predictors for the patient to have longer operative times and greater intra-operative bleeding $(\mathrm{p}<0.250)$. These variables were included in a logistic regression model for each of the outcomes. 


\begin{tabular}{|c|c|c|c|c|c|}
\hline \multirow[b]{2}{*}{ Surgical time } & \multicolumn{2}{|c|}{$\begin{array}{l}\text { Reduced } \\
(n=75)\end{array}$} & \multicolumn{2}{|c|}{$\begin{array}{c}\text { Prolonged } \\
(n=114)\end{array}$} & \multirow[t]{2}{*}{$\mathbf{p}$} \\
\hline & & & & & \\
\hline Female gender & 60 & $(80.0 \%)$ & 02 & $(80.7 \%)$ & $0.905 \dagger$ \\
\hline $\begin{array}{l}\text { Previous oste- } \\
\text { otomy }\end{array}$ & 6 & $(8.0 \%)$ & 48 & $(42.1 \%)$ & $<0.001 \dagger$ \\
\hline $\begin{array}{l}\text { Bilateral dys- } \\
\text { plasia }\end{array}$ & 14 & $(18.7 \%)$ & 48 & $(42.1 \%)$ & $0.001 \dagger$ \\
\hline $\begin{array}{l}\text { Age of articular } \\
\text { replacement } \\
\text { (years) }\end{array}$ & 57.1 & \pm 12.4 & 47.7 & \pm 11.9 & $<0.001 *$ \\
\hline Material removal & 2 & $(2.7 \%)$ & 3 & $(2.6 \%)$ & $0.988 \neq$ \\
\hline $\begin{array}{l}\text { Bone Graft Ap- } \\
\text { plication }\end{array}$ & 2 & $(2.7 \%)$ & 15 & $(13.2 \%)$ & $0.014 \dagger$ \\
\hline \multicolumn{6}{|c|}{$\begin{array}{l}\text { Results of the group are presented in absolute frequencies and } \\
\text { proportions in parentheses, and average } \pm \text { standard deviation; } \\
\text { Cut-off point: } 97 \text { minutes; }{ }^{*} \text { T-student test; } \dagger X^{2} \text { of Pearson; } \ddagger \\
\text { Fisher's exact test }\end{array}$} \\
\hline
\end{tabular}

Table 4: Univariate Analysis of Surgical Time.

\begin{tabular}{|c|c|c|c|c|c|}
\hline \multirow[b]{2}{*}{ Female gender } & \multicolumn{2}{|c|}{$\begin{array}{c}\text { Less* } \\
(n=75)\end{array}$} & \multicolumn{2}{|c|}{$\begin{array}{l}\text { Greater } \\
(\mathrm{n}=114)\end{array}$} & \multirow{2}{*}{$\begin{array}{c}\mathbf{p} \\
0.689 \dagger\end{array}$} \\
\hline & 63 & $(81.8 \%)$ & 89 & (79.5\%) & \\
\hline Previous osteotomy & 13 & $(16.9 \%)$ & 41 & $(36.6 \%)$ & $0.003 \dagger$ \\
\hline Bilateral dysplasia & 15 & $(19.5 \%)$ & 47 & $(42.0 \%)$ & $0.001 \dagger$ \\
\hline $\begin{array}{l}\text { Age of articular re- } \\
\text { placement (years) }\end{array}$ & & \pm 13.1 & & \pm 11.6 & $0.001 *$ \\
\hline Material removal & 2 & $(2.6 \%)$ & 3 & $(2.7 \%)$ & $0.973 \dagger$ \\
\hline $\begin{array}{l}\text { Bone Graft Applica- } \\
\text { tion }\end{array}$ & 1 & $(1.3 \%)$ & 16 & $(14.3 \%)$ & $0.002 \dagger$ \\
\hline \multicolumn{6}{|c|}{$\begin{array}{l}\text { Results of the group are presented in absolute frequencies and } \\
\text { proportions in parentheses and average } \pm \text { deviation standard; } \\
\text { Cut-off point: } 448 \text { milliliters } * \text { T-student test; } \dagger X^{2} \text { of Pearson; } \ddagger \\
\text { Fisher's exact test }\end{array}$} \\
\hline
\end{tabular}

Table 5: Univariate Analysis of Intraoperative Bleeding.

The logistic regression model determined the effect of the selected variables on surgical time, and it was found to be statistically significant $\left(X^{2}=47.941, p<0.001\right)$. The model explains $30.9 \%$ (Nagelkerke's $\mathrm{R}^{2}$ ) of the variance in surgical time and classifies correctly $70.4 \%$ of cases. Of the four predictor variables, only three were statistically significant: age $(\mathrm{OR}=0.96, \mathrm{CI} 95 \%$ [0.93 to 0.98], $\mathrm{P}=0.025)$, previous osteotomies (OR $=5.46$, CI 95\% [2.05 to
14.53], $\mathrm{P}=0.001)$ and bilateral dysplasia $(\mathrm{OR}=3.14, \mathrm{CI} 95 \%[1.48$ to 6.67], $\mathrm{P}=0.003$ ). The area under the ROC curve for this model is $78 \%(0.78, \mathrm{CI} 95 \%,[0.71-0.84], \mathrm{p}<0.001)$, concluding that it is a predictive model, so the probabilities of presenting a prolonged surgical time were calculated based on the explanatory variables (Table 6).

\begin{tabular}{|c|c|c|c|c|}
\hline Age & $\begin{array}{c}\text { Previous } \\
\text { osteotomy } \\
\text { +bilateral } \\
\text { dysplasia }\end{array}$ & $\begin{array}{c}\text { Previous } \\
\text { osteotomy }\end{array}$ & $\begin{array}{c}\text { No prior } \\
\text { dysplasia }\end{array}$ & $\begin{array}{c}\text { Noteral } \\
\text { osteotomy } \\
\text { nor bilateral } \\
\text { dysplasia }\end{array}$ \\
\hline 20 & $82 \%$ & $59 \%$ & $45 \%$ & $21 \%$ \\
\hline 25 & $79 \%$ & $54 \%$ & $40 \%$ & $18 \%$ \\
\hline 30 & $75 \%$ & $49 \%$ & $35 \%$ & $15 \%$ \\
\hline 35 & $71 \%$ & $44 \%$ & $31 \%$ & $12 \%$ \\
\hline 40 & $66 \%$ & $39 \%$ & $27 \%$ & $10 \%$ \\
\hline 45 & $62 \%$ & $34 \%$ & $23 \%$ & $9 \%$ \\
\hline 50 & $57 \%$ & $30 \%$ & $19 \%$ & $7 \%$ \\
\hline 55 & $52 \%$ & $25 \%$ & $16 \%$ & $6 \%$ \\
\hline 60 & $47 \%$ & $22 \%$ & $14 \%$ & $5 \%$ \\
\hline 65 & $42 \%$ & $18 \%$ & $12 \%$ & $4 \%$ \\
\hline 70 & $37 \%$ & $16 \%$ & $10 \%$ & $3 \%$ \\
\hline
\end{tabular}

The calculated probabilities are presented for the coefficients obtained from the regression model according to the formula ; Coefficients: age:-0041, previous osteotomy: 1,697, bilateral dysplasia: 1,145, constant:-0518

Table 6: Probability to have prolonged surgical time depending on explicative variables.

While evaluating the effect of the selected variables on higher postoperative bleeding, the logistic regression model was also found to be statistically significant $\left(\mathrm{X}^{2}=42.799, \mathrm{p}<0.001\right)$. This model explains $27.4 \%$ variance (Nagelkerke's $\mathrm{R}^{2}$ ) in postoperative bleeding. Of the four predictor variables, only three were statistically significant: previous osteotomies $(\mathrm{OR}=6.08, \mathrm{CI} 95 \%$ [2.95 to 12.52], $\mathrm{p}<0.001$ ), bilateral dysplasia (OR $=2.26$, CI $95 \%$ [1.13 to $4.51], \mathrm{P}=0.021)$ and the application of bone graft $(\mathrm{OR}=5.03, \mathrm{CI}$ $95 \%$ [1.46 to 17.57], $\mathrm{P}=0.011$ ). The area under the ROC curve for this model is $70 \%(0.70, \mathrm{CI} 95 \%,[0.61-0.79], \mathrm{p}<0.001)$, concluding that it is a predictive model and hence the probabilities of presenting higher postoperative bleeding were calculated based on the explanatory variables (Table 7). 


\begin{tabular}{|l|c|}
\hline Variable & Probability \\
\hline $\begin{array}{l}\text { Previous osteotomy + bilateral dysplasia + bone } \\
\text { graft }\end{array}$ & $94 \%$ \\
\hline Previous osteotomy + bone graft & $88 \%$ \\
\hline Previous osteotomy + bilateral dysplasia & $77 \%$ \\
\hline Bilateral dysplasia + bone graft & $74 \%$ \\
\hline Previous osteotomy & $61 \%$ \\
\hline Bone Grafting & $54 \%$ \\
\hline Bilateral dysplasia & $36 \%$ \\
\hline All absent & $20 \%$ \\
\hline $\begin{array}{l}\text { The probabilities calculated for the coefficients obtained from } \\
\text { the regression model according to the formula are presented; } \\
\text { Coefficients: bone graft: 1,617, previous osteotomy: 1,805, } \\
\text { bilateral dysplasia: 0815, constant:-1,357 }\end{array}$ \\
\hline
\end{tabular}

Table 7: Probability to have increased postoperative bleeding depending on the explicative variables.

\section{Discussion}

The objective of the study was to determine whether an osteotomy could delay the total hip replacement surgery, we found that the average age at the time of the procedure was earlier in patients with osteotomy when compared with the control group. This results are consistent with the report by Migaud., et al. (55 years vs 57 years) in patients with bone surgery and without bone surgery [19], this does not mean that preservation surgery should be discourage. Previous articles favor the survival of osteotomies [25], but it is proved that is a technically demanding procedure and its results will depend on the experience of the surgeon [26,27], and despite this $70 \%$ will progress to osteoarthrosis [28]. In the literature conversion time of osteotomy to replacement varies from 6 years [29] to 17 years [30], and shorter periods of time (5.9 years) in patients under 40 years [31].

In this cohort, the control group had an average age at the time of the surgery of 55.1 years (range 24-83 years). This results are consistent with data exposed by Cooperman., et al. [32] that reports beginning of arthritis at an age of 57 years old in patients with dysplasia without treatment. Hartofilakidis., et al. [33] describes the natural history of developmental hip dysplasia in relation to osteoarthritis and no treatment, this should be considered the starting point to compare and assess whether or not the development of osteoarthritis is changing in patients with dysplasia who undergo osteotomies. His results are similar to the ones exposed in this paper but he was able to describe the average age of onset of the symptoms at 34.5 years (18-40 years), reach preathritis (stage I) at 37.1 years, degenerative arthritis (stage II) at 43.7 years and severe arthritis (stage III) at 54.8 years and hip arthroplasty done at 51.4 years [33].

Tamaki., et al. describes 3 major pillars of hip preservation which are: increasing the joint surface, preserve muscle strength and creating a favorable condition for arthroplasty in the future [34]. These requirements are not always met, maybe due to pelvic osteotomies interrupting or altering the continuous growth of the acetabulum by early closure of the triradiate cartilage and in the case of femoral osteotomies they can lose correction altering the growth plate leaving a late residual deformity [35], which associated with unpredictable ineffective late natural remodeling can increase the severity of the residual dysplasia [36]. These residual deformities once established could lead to a total hip replacement technically more demanding as reported by Haverkamp., et al. who claimed that one way to assess the difficulty of the surgical procedure is the relationship with time and bleeding [37]. The second objective was to evaluate the degree of technical difficulty in the arthroplasty procedure, measured in surgical time and intraoperative bleeding. This cohort study reports statistically significant differences in bleeding and longer surgical time in the group of previous osteotomies. This finding has been found to be consistent with previous studies on patients with history of Chiari and total hip replacement [23], on patients with previous triple innominate osteotomy (Salter) and posterior hip replacement [16], and on patients with femoral osteotomy as well [38]. Though patients with previous osteotomy had higher intraoperative bleeding, no differences were found in the requirements of transfusion, this could be because these patients were younger and able to cope better with this bleeding.

This study has some limitations. First, the sample of the osteotomy group is modest but we were able to group them in pelvic, femoral or both, which didn't influenced the outcomes of the results. Second, it is a retrospective study, it depends on medical records and on information provided by the patients however it was less than $10 \%$ for the main variables. The major advantage of this cohort study is that all the procedures were performed by a single surgeon, which allows comparison of the outcomes by avoiding the variability of experience and skills for the evaluation of bleeding and surgical times. Also, the main variable of this study is the age at which the procedure was performed (total hip replacement), a variable that is unmodifiable in the medical records. 


\section{Conclusion}

This study proposes the beginning of a research line where the patients can be monitored during childhood and defining factors can be evaluated to overcome the disadvantages of this study. With our results we can aver that patients with osteotomies around the hip required early hip arthroplasty $(42.2 \pm 9.4$ years vs. $55.1 \pm 12.3$ years $\mathrm{p}<0.001$ ), and this procedure had longer surgical times $(\mathrm{OR}=5.46, \mathrm{P}=0.001)$ and increased intraoperative bleeding (OR $=6.08, \mathrm{p}<0.001$ ). Osteotomies cannot be discouraged as a treatment for childhood dysplasia, but the indications of these treatments and the experience and skill of the surgeon must be evaluated [27], since in most cases it is not limited to a single procedure and does not always improve the natural history of the disease.

\section{Bibliography}

1. Loder RT and Skopelja EN. "The Epidemiology and Demographics of Hip Dysplasia”. ISRN Orthopaedics (2011): 1-46.

2. Carlos R. “Cadera congénita”. Ccap 06 (2011): 5-20.

3. Tonnis D. "Nomenclature and classification of congenital hip dislocation". In: Congenital dysplasia and dislocation of the hip in children and adults (1987): 80-83.

4. Severin E. "Congenital dislocation of the hip development of the joint after closed reduction". Journal of Bone and Joint Surgery 32 (1950): 507-518.

5. Crowe J., et al. "Total Hip Replacement in Congenital Dislocation and Dysplasia of the Hip". Journal of Bone and Joint Surgery 61 (1979): 15-23.

6. Hartofilakidis G., et al. "Congenital hip disease in adults Classification of Acetabular Deficiencies and Operative Treatment with Acetabuloplasty Combined with Total Hip Arthroplasty". Journal of Bone and Joint Surgery-American 78-A (1996): 683692.

7. Albinana J., et al. "Acetabular dysplasia after treatment for developmental dysplasia of the hip". Journal of Bone and Joint Surgery-American 86.6 (2004): 876-886.

8. Wyles CC., et al. "The John Charnley Award: Redefining the Natural History of Osteoarthritis in Patients With Hip Dysplasia and Impingement". Clinical Orthopaedics and Related Research 475.2 (2017): 336-350.

9. Hasegawa Y., et al. "The natural course of osteoarthritis of the hip due to subluxation or acetabular dysplasia". Archives of Orthopaedic and Trauma Surgery 111 (1992): 187-191.
10. Greber EM., et al. "Challenges in Total Hip Arthroplasty in the Setting of Developmental Dysplasia of the Hip". Journal of Arthroplasty 32.9 (2017): S38-44.

11. Sanchez-Sotelo J., et al. "Surgical treatment of developmental dysplasia of the hip in adults: I. Nonarthroplasty options". Journal of the American Academy of Orthopaedic Surgeons 10.5 (2002): 321-333.

12. Huang Z., et al. "A clinical comparative study of anatomic parameters before and after total hip replacement on congenital dysplasia". Journal of Physical Therapy Science 28 (2016): 1953-1956.

13. Cooperman DR., et al. "Acetabular dysplasia in the adult". Clinical Orthopaedics and Related Research 175 (1983): 79-85.

14. Duncan S., et al. "Does previous osteotomy compromise total hip arthroplasty? A systematic review". Journal of Arthroplasty 30.1 (2015): 79-85.

15. Amanatullah DF., et al. "Similar Clinical Outcomes for THAs With and Without Prior Periacetabular Osteotomy". Clinical Orthopaedics and Related Research 473 (2015): 685-691.

16. Peters CL., et al. "Total hip arthroplasty in young adults after failed triple innominate osteotomy". Journal of Arthroplasty 16.2 (2001): 188-195.

17. Kawasaki M., et al. "Total hip arthroplasty after failed transtrochanteric rotational osteotomy for avascular necrosis of the femoral head". Journal of Arthroplasty 20.5 (2005): 574-579.

18. Li H., et al. "Comparison of Total Hip Arthroplasty With and Without Femoral Shortening Osteotomy for Unilateral Mild to Moderate High Hip Dislocation". Journal of Arthroplasty 32.3 (2017): 849-856.

19. Migaud H., et al. "Does prior conservative surgery affect survivorship and functional outcome in total hip arthroplasty for congenital dislocation of the hip? A case-control study in 159 hips". (2014).

20. Osawa Y., et al. "Total Hip Arthroplasty After Periacetabular and Intertrochanteric Valgus Osteotomy". Journal of Arthroplasty 32.3 (2017): 857-861.

21. Osawa Y., et al. "Significantly Poor Outcomes of Total Hip Arthroplasty After Failed Periacetabular Osteotomy". Journal of Arthroplasty 31.9 (2016): 1904-1909.

22. Clohisy JC., et al. "A Systematic Approach to the Plain Radiographic Evaluation of the Young Adult Hip". Journal of Bone and Joint Surgery-American 90 (2008): 47-66. 
23. Minoda Y., et al. "Total hip arthroplasty of dysplastic hip after previous Chiari pelvic osteotomy". Archives of Orthopaedic and Trauma Surgery 126.6 (2006): 394-400.

24. Tamaki T., et al. "Total Hip Arthroplasty after Previous Acetabular Osteotomy: Comparison of Three Types of Acetabular Osteotomy". 31 (2016): 172-175.

25. Steppacher SD., et al. "Mean 20-year followup of bernese periacetabular osteotomy". Clinical Orthopaedics and Related Research 466.7 (2008): 1633-1644.

26. Novais EN., et al. "Does Surgeon Experience Impact the Risk of Complications After Bernese Periacetabular Osteotomy?" Clinical Orthopaedics and Related Research (2017): 11101117.

27. Howie DW., et al. "Mentoring in complex surgery : minimising the learning curve complications from peri-acetabular osteotomy". International Orthopaedics (2012): 921-925.

28. Lerch TD., et al. "One-third of Hips After Periacetabular Osteotomy Survive 30 Years With Good Clinical Results, No Progression of Arthritis, or Conversion to THA". Clinical Orthopaedics and Related Research 475.4 (2016): 1154-1168.

29. Søballe K., et al. "Total hip replacement after medial-displacement osteotomy of the proximal part of the femur". Journal of Bone and Joint Surgery -American 71.5 (1989): 692-697.

30. Hashemi-Nejad A., et al. "Does Chiari osteotomy compromise subsequent total hip arthroplasty?". Journal of Arthroplasty 17.6 (2002): 731-739.

31. Gray BL., et al. "Comparison of contemporary periacetabular osteotomy for hip dysplasia with total hip arthroplasty for hip osteoarthritis". Journal of Bone and Joint-British 97-B.10 (2015): 1322-1327.

32. Cooperman D. "What is the evidence to support acetabular dysplasia as a cause of osteoarthritis?" Journal of Pediatric Orthopaedics 33 (2013): S2-7.

33. Hartofilakidis G., et al. "Epidemiology, demographics, and natural history of congenital hip disease in adults". Orthopedics 23.8 (2000): 823-827.

34. Tamaki T., et al. "Total Hip Arthroplasty after Previous Acetabular Osteotomy: Comparison of Three Types of Acetabular Osteotomy". Journal of Arthroplasty 31.1 (2015): 172-175.

35. Lee MC and Eberson CP. "Growth and Development of the Child's Hip". Orthopedic Clinics of North America 37.2 (2006): 119-132.
36. Thomas SR., et al. "Outcome at Forty-five Years After Open Reduction and Innominate Osteotomy for Late-Presenting Developmental Dislocation of the Hip". Journal of Bone and Joint Surgery-American 89 (2007): 2341-2350.

37. Haverkamp D., et al. "Intertrochanteric osteotomies do not impair long-term outcome of subsequent cemented total hip arthroplasties". Clinical Orthopaedics and Related Research 444.5 (2006): 154-160.

38. Lee YK., et al. "Total Hip Arthroplasty After Previous Transtrochanteric Anterior Rotational Osteotomy for Femoral Head Osteonecrosis". Journal of Arthroplasty 24.8 (2009): 1205-1209.

\section{Assets from publication with us}

- Prompt Acknowledgement after receiving the article

- Thorough Double blinded peer review

- Rapid Publication

- Issue of Publication Certificate

- High visibility of your Published work

Website: https://www.actascientific.com/

Submit Article: https://www.actascientific.com/submission.php

Email us: editor@actascientific.com

Contact us: +919182824667 